\title{
Usefulness of Multiplex Real-Time PCR for Simultaneous Pathogen Detection and Resistance Profiling of Staphylococcal Bacteremia
}

\author{
Yousun Chung, ${ }^{1}$ Taek Soo Kim, ${ }^{2}$ Young Gi Min, ${ }^{2}$ Yun Ji Hong, ${ }^{3}$ \\ Jeong Su Park, ${ }^{3}$ Sang Mee Hwang, ${ }^{3}$ Kyoung-Ho Song, ${ }^{4}$ Eu Suk Kim, ${ }^{4}$ Kyoung Un Park, ${ }^{1,3}$ \\ Hong Bin Kim, ${ }^{4}$ Junghan Song, ${ }^{1,3}$ and Eui-Chong Kim ${ }^{1,2}$ \\ ${ }^{1}$ Department of Laboratory Medicine, Seoul National University College of Medicine, 101 Daehak-ro, Jongno-gu, \\ Seoul 03080, Republic of Korea \\ ${ }^{2}$ Department of Laboratory Medicine, Seoul National University Hospital, 101 Daehak-ro, Jongno-gu, Seoul 03080, Republic of Korea \\ ${ }^{3}$ Department of Laboratory Medicine, Seoul National University Bundang Hospital, 82 Gumi-ro, 173 Beon-gil, Bundang-gu, \\ Seongnam-si, Gyeonggi-do 13620, Republic of Korea \\ ${ }^{4}$ Department of Internal Medicine, Seoul National University Bundang Hospital, 82 Gumi-ro, 173 Beon-gil, Bundang-gu, \\ Seongnam-si, Gyeonggi-do 13620, Republic of Korea
}

Correspondence should be addressed to Kyoung Un Park; m91w95pf@snu.ac.kr

Received 24 March 2016; Accepted 23 May 2016

Academic Editor: Giulio Mengozzi

Copyright (C) 2016 Yousun Chung et al. This is an open access article distributed under the Creative Commons Attribution License, which permits unrestricted use, distribution, and reproduction in any medium, provided the original work is properly cited.

Staphylococci are the leading cause of nosocomial blood stream infections. Fast and accurate identification of staphylococci and confirmation of their methicillin resistance are crucial for immediate treatment with effective antibiotics. A multiplex real-time PCR assay that targets $m e c A$, femA specific for $S$. aureus, femA specific for S. epidermidis, $16 S \mathrm{rRNA}$ for universal bacteria, and $16 S$ rRNA specific for staphylococci was developed and evaluated with 290 clinical blood culture samples containing Grampositive cocci in clusters (GPCC). For the 262 blood cultures identified to the species level with the MicroScan WalkAway system (Siemens Healthcare Diagnostics, USA), the direct real-time PCR assay of positive blood cultures showed very good agreement for the categorization of staphylococci into methicillin-resistant S. aureus (MRSA), methicillin-susceptible S. aureus (MSSA), methicillin-resistant S. epidermidis (MRSE), methicillin-susceptible S. epidermidis (MSSE), methicillin-resistant non-S. epidermidis CoNS (MRCoNS), and methicillin-susceptible non-S. epidermidis CoNS (MSCoNS) $(\kappa=0.9313)$. The direct multiplex real-time PCR assay of positive blood cultures containing GPCC can provide essential information at the critical point of infection with a turnaround time of no more than $4 \mathrm{~h}$. Further studies should evaluate the clinical outcome of using this rapid real-time PCR assay in glycopeptide antibiotic therapy in clinical settings.

\section{Introduction}

Staphylococci are the most commonly isolated organisms in clinical laboratories, accounting for almost $30 \%$ of all nosocomial infections and 50\% of nosocomial bloodstream infections [1]. Staphylococcus aureus is the leading cause of nosocomial infections [2], and methicillin-resistant $S$. aureus (MRSA) infections result in significant morbidity, mortality, and longer hospital stays if not treated early with effective antibiotics [3]. Coagulase-negative staphylococci (CoNS) are the most common isolates from blood culture, and more than
$70 \%$ are resistant to oxacillin [4]. Although they are known to contaminate blood cultures as a result of their colonization on the skin and mucous membranes, they have recently become important pathogens causing nosocomial infections with the increasing use of invasive procedures and prosthetic devices $[5,6]$. Fast and accurate identification of staphylococci and confirmation of their methicillin resistance are crucial for immediate treatment with effective antibiotics, which will result in decreased morbidity and mortality rates [7].

The conventional culture method for the identification and susceptibility testing of positive blood cultures has 
TABLE 1: PCR primers and TaqMan probes for mecA, femA specific for S. aureus (femA-SA), femA specific for S. epidermidis (femA-SE), and universal $16 S$ rRNA and PCR primers for staphylococcal $16 S$ rRNA.

\begin{tabular}{|c|c|}
\hline Target genes & Sequence \\
\hline \multirow{3}{*}{ mecA } & $5^{\prime}$-CATTGATCGCAACGTTCAATTT-3' \\
\hline & $5^{\prime}$-TGGTCTTTCTGCATTCCTGGA-3' \\
\hline & $5^{\prime}$-FAM-TGGAAGTTAGATTGGGATCATAGCGTCAT-TAMRA-3' \\
\hline \multirow{3}{*}{ femA-SA } & $5^{\prime}$-TGCCTTTACAGATAGCATGCCA-3' \\
\hline & $5^{\prime}$-AGTAAGTAAGCAAGCTGCAATGACC-3' \\
\hline & 5'-JOE-TCATTTCACGCAAACTGTTGGCCACTATG-BHQ1-3' \\
\hline \multirow{3}{*}{ femA-SE } & $5^{\prime}$-CAACTCGATGCAAATCAGCAA- $3^{\prime}$ \\
\hline & 5'-GAACCGCATAGCTCCCTGC-3’ \\
\hline & 5'-JOE-TACTACGCTGGTGGAACTTCAAATCGTTATCG-BHQ1-3' \\
\hline \multirow{3}{*}{ Universal $16 S$ rRNA } & $5^{\prime}$-TCCTACGGGAGGCAGCAGT-3' \\
\hline & $5^{\prime}$-GGACTACCAGGGTATCTAATCCTGTT-3' \\
\hline & 5'-FAM-CGTATTACCGCGGCTGCTGGCAC-TAMRA-3' \\
\hline \multirow{2}{*}{ Staphylococcal $16 S$ rRNA } & 5'-GCAAGCGTTATCCGGATTT-3' \\
\hline & $5^{\prime}$-CTTAATGATGGCAACTAAGC-3' \\
\hline
\end{tabular}

some disadvantages, including long turnaround time and potential false-negative results when samples are obtained after antimicrobial therapy. Real-time PCR is significantly faster than conventional PCR and other detection methods, and its excellent sensitivity and specificity, low contamination risk, ease of use, and high speed have made real-time PCR technology appealing to clinical microbiology laboratories [8].

The aim of this study was to develop and evaluate a multiplex real-time PCR assay for the rapid detection and identification of MRSA, methicillin-susceptible S. aureus (MSSA), methicillin-resistant S. epidermidis (MRSE), methicillinsusceptible $S$. epidermidis (MSSE), methicillin-resistant nonS. epidermidis CoNS (MRCoNS), and methicillin-susceptible non-S. epidermidis CoNS (MSCoNS) directly from positive blood cultures containing Gram-positive cocci in clusters (GPCC) by targeting $m e c A$ for determining methicillin resistance, femA specific for $S$. aureus (femA-SA), femA specific for S. epidermidis (femA-SE), $16 S$ rRNA for universal bacteria, and $16 S$ rRNA specific for staphylococci.

\section{Materials and Methods}

2.1. Blood Culture. This study evaluated 290 blood cultures containing GPCC obtained from March 2013 to December 2013 at Seoul National University Bundang Hospital. Two or more pairs of culture bottles for aerobes or anaerobes were incubated in BacT/Alert 3D (bioMérieux Inc., Durham, NC, USA) or BACTEC FX (BD Diagnostics, Sparks, MD, USA) blood culture systems for 5 days after inoculation for blood drawn from the patient. If bacterial growth was not detected within 5 days, then the blood culture result was considered negative. When bacterial growth was noted, blood from the positive bottles was Gram-stained, and samples containing GPCC (230 specimens in BacT/Alert 3D (bioMérieux Inc.) and 60 specimens in BACTEC FX (BD Diagnostics)) were inoculated onto blood agar plates and cultured overnight at $35^{\circ} \mathrm{C}$ in a $5 \% \mathrm{CO}_{2}$ incubator. Isolates were identified by colony morphology, Gram-staining, catalase, and coagulase tests.
Final identification according to phenotypic characteristics and antimicrobial susceptibility tests was performed using the MicroScan WalkAway system (Siemens Healthcare Diagnostics, Deerfield, IL, USA) with Pos Combo Panel Type 1A.

2.2. DNA Extraction. A $100 \mu \mathrm{L}$ aliquot of blood was drawn directly from the positive blood culture bottles, collected on filter paper, and dried for $15 \mathrm{~min}$ at room temperature. The blood spot was lysed with $2 \mathrm{~mL}$ of lysis buffer for $30 \mathrm{~min}$ at room temperature. Next, the paper was removed, and $2 \mu \mathrm{L}$ of lysozyme-Tris-EDTA buffer was added to $500 \mu \mathrm{L}$ of the eluate and incubated for $30 \mathrm{~min}$ at $37^{\circ} \mathrm{C}$. The sample was incubated again for $10 \mathrm{~min}$ in $2 \mathrm{~mL}$ of lysis buffer, and the final eluate was used for nucleic acid extraction with the NucliSENS easyMAG platform (bioMérieux Inc.).

2.3. Multiplex Real-Time PCR Assay Targeting mecA, femA$S A$, femA-SE, and Universal $16 S$ rRNA. The double duplex real-time PCR TaqMan assay was performed with two tubes in one reaction. One tube corresponded to the targets femASA and mecA and the other to the targets femA-SE and universal $16 S r R N A$. The primers and probes for each target were designed as described by previously published studies $[9,10]$ (Table 1). Real-time PCR was conducted in a total volume of $20 \mu \mathrm{L}$, including $2.0 \mu \mathrm{L}$ of $10 \mathrm{x}$ LightCycler FastStart DNA Master HybProbe (Roche Diagnostics, Mannheim, Germany), $2.4 \mu \mathrm{L}$ of $15 \mathrm{mM} \mathrm{MgCl}_{2}$ (Takara Bio, Shiga, Japan), $0.2 \mu \mathrm{M}$ of each primer, and $0.1 \mu \mathrm{M}$ of each probe with $3.0 \mu \mathrm{L}$ of DNA template. The amplification conditions used by the m2000rt instrument (Abbott Diagnostic, Chicago, IL, USA) were as follows: $95^{\circ} \mathrm{C}$ for $10 \mathrm{~min}$ followed by 35 cycles of $95^{\circ} \mathrm{C}$ for $15 \mathrm{sec}$ and $60^{\circ} \mathrm{C}$ for $1 \mathrm{~min}$ in a single real-time PCR assay. Positive controls with MRSA, MSSA, and MRSE and a negative control with sterile distilled water (DW) were included throughout the procedures.

2.4. Additional Real-Time PCR Assay Targeting Staphylococcal $16 S$ rRNA. A real-time PCR assay targeting staphylococcal $16 S$ rRNA was performed using a LightCycler 2.0 system 
TABLE 2: Interpretation of results by real-time PCR assays.

\begin{tabular}{lccccc}
\hline & mecA & femA-SA & femA-SE & Universal & Staphylococcal \\
16S rRNA & P $r R N A$ \\
\hline MRSA & $\mathrm{P}^{\mathrm{c}}$ & $\mathrm{P}$ & $\mathrm{N}^{\mathrm{d}}$ & $\mathrm{P}$ & $\mathrm{P}$ \\
MSSA & $\mathrm{N}$ & $\mathrm{P}$ & $\mathrm{N}$ & $\mathrm{P}$ & $\mathrm{P}$ \\
MRSE & $\mathrm{P}$ & $\mathrm{N}$ & $\mathrm{P}$ & $\mathrm{P}$ & $\mathrm{P}$ \\
MSSE & $\mathrm{N}$ & $\mathrm{N}$ & $\mathrm{P}$ & $\mathrm{P}$ & $\mathrm{P}$ \\
MRCoNS & $\mathrm{P}$ & $\mathrm{N}$ & $\mathrm{N}$ & $\mathrm{P}$ & $\mathrm{P}$ \\
MSCoNS & $\mathrm{N}$ & $\mathrm{N}$ & $\mathrm{N}$ & $\mathrm{P}$ & $\mathrm{N}$ \\
Nonstaphylococci & $\mathrm{P}$ or N & $\mathrm{N}$ & $\mathrm{N}$ & & \\
\hline
\end{tabular}

a femA specific for $S$. aureus.

${ }^{\mathrm{b}}$ femA specific for S. epidermidis.

${ }^{\mathrm{c}}$ Positive.

${ }^{\mathrm{d}}$ Negative.

(Roche Diagnostics) for the detection of staphylococci. Primers targeting staphylococcal $16 S$ rRNA were designed as described in a previously published study [11] (Table 1). Amplification reactions were performed in a $20 \mu \mathrm{L}$ volume containing $2 \mu \mathrm{L}$ of DNA template, $0.25 \mu \mathrm{M}$ of each primer, and $10 \mu \mathrm{L}$ of $2 \mathrm{x}$ SYBR Premix Ex Taq (Takara Bio). The conditions consisted of an initial denaturation at $95^{\circ} \mathrm{C}$ for $10 \mathrm{~min}$ followed by amplification program for 30 cycles of $10 \mathrm{sec}$ at $95^{\circ} \mathrm{C}, 20 \mathrm{sec}$ at $58^{\circ} \mathrm{C}$, and $20 \mathrm{sec}$ at $74^{\circ} \mathrm{C}$ with fluorescence acquisition at the end of each cycle. The amplification program was followed by a melting program consisting of heating to $95^{\circ} \mathrm{C}$ with a $0 \mathrm{sec}$ hold and $15 \mathrm{sec}$ at $60^{\circ} \mathrm{C}$ and a gradual increase to $99^{\circ} \mathrm{C}$ at a rate of $0.1^{\circ} \mathrm{C} / \mathrm{sec}$ with fluorescence acquisition at each temperature transition. Positive controls with MRSA, MSSA, and MRSE and a negative control with sterile DW were included throughout the procedure. The existence of the target was confirmed by melting curve analysis. If the melting temperature ( $\mathrm{Tm}$ ) of the samples was within $0.5^{\circ} \mathrm{C}$ of the Tm of the positive control's product, they were regarded as positive.

All the above-mentioned real-time PCR assays were repeated with DNA extracted with subcultured colonies for comparison with the direct specimens.

2.5. Categorization of Real-Time PCR Results. Using a double duplex real-time PCR assay, the detection of femA-SA and universal 16S rRNA indicated the presence of MSSA, while the detection of femA-SA, mecA, and universal $16 S$ $r R N A$ indicated the presence of MRSA. If femA-SE and universal $16 S$ rRNA were detected, the presence of MSSE was inferred, while the detection of femA-SE, mecA, and universal $16 S r R N A$ indicated the presence of MRSE. The detection of mecA and universal $16 S r R N A$ was interpreted as indicating the presence of MRCoNS or methicillinresistant nonstaphylococci, while the detection of universal $16 S$ rRNA alone was interpreted as indicating the presence of MSCoNS or methicillin-susceptible nonstaphylococci. The additional PCR test targeting staphylococcal $16 S$ rRNA confirmed whether the isolate was staphylococci. The detection of universal $16 S \mathrm{rRNA}$, but not staphylococcal $16 S \mathrm{rRNA}$, was interpreted as indicating the presence of bacteria other than staphylococci (Table 2). The real-time PCR results were compared with MicroScan identification and susceptibility results as a reference.

\section{Results}

3.1. Identification Results Obtained with the MicroScan WalkAway System (Siemens Healthcare Diagnostics). Of the 290 positive blood cultures with GPCC, 262 cultures were identified to the species level by MicroScan as follows: $89 \mathrm{~S}$. aureus, 96 S. epidermidis, 27 S. hominis, 26 S. capitis, 9 S. haemolyticus, 5 S. capitis subsp. urealyticus, 2 Staphylococcus saprophyticus, 2 S. lugdunensis, 2 S. hominis subsp. hominis, 1 S. cohnii, 1 S. auricularis, 1 S. schleiferi, and 1 S. schleiferi subsp. coagulans. Fifteen isolates showed low-probability identification, with multiple possible staphylococcal species, and the remaining 13 isolates were nonstaphylococci, including 12 Micrococcus species and 1 Enterococcus faecalis.

3.2. Comparison of Results Obtained by Real-Time PCR with Direct Specimens and the Results of the MicroScan WalkAway System (Siemens Healthcare Diagnostics). The real-time PCR identification of MRSA correlated with the MicroScan results for 46 out of 47 specimens. The discordant one was identified as MSSA by MicroScan. The real-time PCR identification of MSSA correlated with the MicroScan results for all 42 isolates.

Eighty-five out of 96 blood cultures identified as containing MRSE by real-time PCR were confirmed by MicroScan, while four isolates were identified as MRCoNS and two as MSSE. The MicroScan results for the remaining five isolates were low-probability identifications with multiple possible staphylococcal species that were all resistant to methicillin. The real-time PCR identification of MSSE correlated with the MicroScan results for seven out of eight isolates; the discordant isolate was identified as MSCoNS by MicroScan.

A total of 50 out of 58 blood cultures containing MRCoNS, as determined by real-time PCR, were confirmed to be MRCoNS with MicroScan, while one isolate was identified as MRSE and another as MSCoNS. The MicroScan results for the remaining six isolates were low-probability identifications with multiple possible staphylococcal species that were all resistant to methicillin. Eighteen out of 26 
TABLE 3: Comparison of results by real-time PCR with direct specimen and results by MicroScan WalkAway system (thirteen isolates of nonstaphylococci are excluded.).

\begin{tabular}{|c|c|c|c|c|c|c|}
\hline \multirow{2}{*}{ MicroScan WalkAway system } & \multicolumn{6}{|c|}{ Real-time PCR assays with direct specimen } \\
\hline & MRSA $^{\mathrm{a}}$ & MSSA $^{\mathrm{b}}$ & $\mathrm{MRSE}^{\mathrm{c}}$ & $\operatorname{MSSE}^{\mathrm{d}}$ & MRCoNS $^{e}$ & MSCoNS $^{\mathrm{f}}$ \\
\hline MRSA & 46 & - & - & - & - & - \\
\hline MSSA & 1 & 42 & - & - & - & - \\
\hline MRSE & - & - & 85 & - & 1 & - \\
\hline MSSE & - & - & 2 & 7 & - & 1 \\
\hline MRCoNS & - & - & 4 & - & 50 & 3 \\
\hline MSCoNS & - & - & - & 1 & 1 & 18 \\
\hline Unidentified staphylococci* & - & - & 5 & - & 6 & 4 \\
\hline
\end{tabular}

* All the results of mecA were in concordance with phenotypic methicillin resistance.

${ }^{\text {a }}$ Methicillin-resistant $S$. aureus.

${ }^{\mathrm{b}}$ Methicillin-susceptible $S$. aureus.

${ }^{\mathrm{c}}$ Methicillin-resistant S. epidermidis.

${ }^{\mathrm{d}}$ Methicillin-susceptible S. epidermidis.

${ }^{\mathrm{e}}$ Methicillin-resistant non-S. epidermidis CoNS.

${ }^{\mathrm{f}}$ Methicillin-susceptible non-S. epidermidis CoNS.

blood cultures containing MSCoNS by real-time PCR were confirmed by MicroScan, while three were identified as MRCoNS and one as MSSE. The MicroScan results for the remaining four isolates were low-probability identifications with multiple possible staphylococcal species that were all sensitive to methicillin. Thirteen isolates that were interpreted as nonstaphylococci by real-time PCR were confirmed as 12 Micrococcus species and 1 Enterococcus faecalis by MicroScan system.

For the 262 blood cultures identified to the species level by MicroScan, the results agreed very well with those obtained by real-time PCR for staphylococcal species categorization into MRSA, MSSA, MRSE, MSSE, MRCoNS, and MSCoNS (Cohen's unweighted kappa coefficient $\kappa=0.9313$ ) (Table 3). The sensitivity and specificity of mecA, femA-SA, femA-SE, universal 16S $r R N A$, and staphylococcal 16S $r R N A$ were evaluated with the 262 blood cultures according to the MicroScan results. The sensitivity and specificity were, respectively, $98.4 \%$ and $94.5 \%$ for the $m e c A$ gene, $100.0 \%$ and $100.0 \%$ for femA-SA, $97.9 \%$ and $97.0 \%$ for femA-SE, $100.0 \%$ and $100.0 \%$ for universal $16 S$ rRNA, and $100.0 \%$ and $100.0 \%$ for staphylococcal 16S rRNA (Table 4).

3.3. Comparison of the Results Obtained by Real-Time PCR with Direct Specimens and Real-Time PCR with Subcultured Colonies. The real-time PCR results of direct specimens correlated with the PCR results of subcultured colonies for 282 of 290 samples. The results for 14 out of the 282 concordant samples were discordant with the MicroScan results. Of the seven samples that were interpreted as MRSE by both real-time PCR techniques, three were identified by MicroScan as MSCoNS, three as methicillin-resistant staphylococci (not identified to the species level), and one as MSSE. In two samples identified as MRCoNS by both real-time PCR techniques, the MicroScan identifications were MRSE and MSCoNS. Of the four samples identified as MSCoNS by both real-time PCR techniques, one was identified by MicroScan as MSSE and the other three were identified
TABle 4: Sensitivity and specificity of $m e c A$, femA specific for S. aureus (femA-SA), femA specific for S. epidermidis (femA-SE), universal $16 S$ rRNA, and staphylococcal $16 S$ rRNA.

\begin{tabular}{lcc}
\hline Target genes & Sensitivity (\%) & Specificity (\%) \\
\hline mecA & 98.4 & 94.5 \\
femA-SA & 100.0 & 100.0 \\
femA-SE & 97.9 & 97.0 \\
Universal 16S rRNA & 100.0 & 100.0 \\
Staphylococcal 16S rRNA & 100.0 & 100.0 \\
\hline
\end{tabular}

as MRCoNS. The remaining sample identified as MSSE by both real-time PCR techniques was identified as MSCoNS by MicroScan.

There were eight discordant results between real-time PCR with direct specimens and real-time PCR with subcultured colonies. In two samples that were identified as MSSA and MSSE by MicroScan, only real-time PCR with direct specimens detected mecA. In one sample, identified as MRCoNS by MicroScan, only real-time PCR with direct specimens detected femA-SE. In another sample, identified as MRSA by MicroScan, only real-time PCR with colonies failed to detect femA-SA. Finally, in the remaining four samples, which were identified as MRSE by MicroScan, only real-time PCR with colonies failed to detect femA-SE. The discordant results for the three methods are shown in Table 5.

\section{Discussion}

In this study, a multiplex real-time PCR assay that targets mecA, femA-SA, femA-SE, universal bacterial 16S rRNA, and staphylococci-specific $16 \mathrm{~S}$ rRNA was developed and evaluated with clinical samples for the rapid identification of GPCC and determination of methicillin susceptibility. Overall, there was very good agreement between the realtime PCR with direct specimens and the MicroScan system for the 290 blood cultures, indicating reliable categorization 
TABLE 5: The discordant results between real-time PCR with direct specimen, real-time PCR with subcultured colonies, and MicroScan WalkAway system.

\begin{tabular}{|c|c|c|c|}
\hline $\begin{array}{l}\text { Real-time PCR with } \\
\text { direct specimen }\end{array}$ & $\begin{array}{l}\text { Real-time PCR with subcultured } \\
\text { colonies }\end{array}$ & $\begin{array}{c}\text { MicroScan } \\
\text { Walkaway system } \\
\end{array}$ & Number \\
\hline $\mathrm{MRSE}^{\mathrm{a}}$ & MRSE & $\mathrm{MRCoNS}^{\mathrm{b}}$ & 3 \\
\hline MRSE & MRSE & $\operatorname{MSSE}^{\mathrm{c}}$ & 1 \\
\hline MRSE & MRSE & MR staphylococci & 3 \\
\hline MSSE & MSSE & $\mathrm{MSCoNS}^{\mathrm{d}}$ & 1 \\
\hline MRCoNS & MRCoNS & MRSE & 1 \\
\hline MRCoNS & MRCoNS & MSCoNS & 1 \\
\hline MSCoNS & MSCoNS & MSSE & 1 \\
\hline MSCoNS & MSCoNS & MRCoNS & 3 \\
\hline MRSA $^{\mathrm{e}}$ & $\operatorname{MSSA}^{\mathrm{f}}$ & MSSA & 1 \\
\hline MRSA & MRCoNS & MRSA & 1 \\
\hline MRSE & MSSE & MSSE & 1 \\
\hline MRSE & MRCoNS & MRCoNS & 1 \\
\hline MRSE & MRCoNS & MRSE & 4 \\
\hline
\end{tabular}

${ }^{a}$ MRSE, methicillin-resistant $S$. epidermidis.

${ }^{\mathrm{b}} \mathrm{MRCoNS}$, methicillin-resistant non-S. Epidermidis CoNS.

${ }^{\mathrm{c}}$ MSSE, methicillin-susceptible S. epidermidis.

${ }^{\mathrm{d}}$ MSCoNS, methicillin-susceptible non-S. epidermidis CoNS.

${ }^{\mathrm{e}}$ MRSA, methicillin-resistant $S$. aureus.

${ }^{\mathrm{f}}$ MSSA, methicillin-susceptible S. aureus.

as MRSA, MSSA, MRSE, MSSE, MRCoNS, MSCoNS, and nonstaphylococci.

Real-time PCR correctly identified all 46 positive blood cultures, which were confirmed as MRSA by MicroScan. Of the 43 blood cultures identified as MSSA by MicroScan, all but one were identified as MSSA by real-time PCR; the discordant culture was identified as MRSA by real-time PCR and as MSSA by additional PCR with subcultured colonies. This result could be due to nonspecific amplification of the $m e c A$ gene, but the presence of the mecA gene at a very low level in the positive blood bottle is also a potential explanation. There were no $S$. aureus isolates that were identified as mecA negative by real-time PCR but methicillin-resistant by MicroScan. It would be more troublesome if methicillinresistant strains were not detected by PCR because these cases are likely to result in treatment failures.

In two out of 96 cultures identified as S. epidermidis by MicroScan, the femA-SE gene was not detected by realtime PCR with direct specimens or real-time PCR with subcultured colonies. As suggested by the manufacturers of MicroScan, we used a cut-off of $85 \%$ for identification at the species level as indicating a high probability and no additional tests required. However, previous studies have reported the misidentification of staphylococci by MicroScan, and misidentification by MicroScan is also a possibility in these cases $[12,13]$.

The mecA gene was detected by real-time PCR in all 86 blood cultures that were identified as MRSE by MicroScan. In two samples out of 10 blood cultures identified as MSSE by MicroScan, mecA was detected by real-time PCR. PCR testing using DNA from the subcultured colonies was positive for $m e c A$ in one sample but negative in the other sample. In the case of positive mecA identification by both PCR assays (direct specimen and subcultured colonies) but identification as methicillin-susceptible by MicroScan, there is a possibility of false oxacillin susceptibility results due to the heteroresistance phenomenon, which is a consequence of the complex regulation of the phenotypic expression of the mecA gene $[14,15]$.

Among the 57 isolates identified as MRCoNS by MicroScan, three were negative in $m e c A$ using real-time PCR directly from the blood culture bottles and additional PCR with subcultured colonies. This result could be attributed to false-negatives due to the possible limitations of PCR assays, such as the presence of PCR inhibitors. However, another possible explanation is a resistance mechanism other than mecA. Strains without the mecA gene can acquire methicillin resistance modification of normal PBP genes or overproduction of staphylococcal $\beta$-lactamase, resulting in methicillin resistance [16-18]. There were two discordant results out of 20 blood cultures identified as MSCoNS by MicroScan. In one sample, mecA was detected by both realtime PCR assays (direct specimen and subcultured colonies), while femA-SE genes were detected in the other sample by both real-time PCR assays.

For the fifteen staphylococci that were not identified to the species level by MicroScan, the mecA results were all in concordance with phenotypic methicillin resistance. And for the thirteen isolates identified as Micrococci and Enterococci by MicroScan, only universal $16 S r R N A$ genes were detected by real-time PCR assays.

One limitation of this assay is that it cannot determine methicillin resistance of $S$. aureus when staphylococci other than $S$. aureus are also detected as mixed culture with positive 
$m e c A$. Unlike conventional identification and susceptibility testing, multiplex real-time PCR assay is unable to indicate methicillin resistance to each of the staphylococci when it comes to mixed culture $[19,20]$. It would be important to incorporate the multiplex real-time PCR assay alongside conventional identification and susceptibility testing.

In a clinical laboratory setting, the rapid and reliable identification of staphylococci and the determination of their methicillin susceptibility are important for effective antibiotic therapy and avoidance of the inappropriate use of glycopeptides [21]. Conventional identification and susceptibility testing of positive blood cultures based on phenotypic characteristics can take up to $48 \mathrm{~h}$ after the GPCC are recognized by Gram-staining. For prompt initiation with optimal antibiotic therapy, clinical laboratories are incorporating molecular diagnostic methods, such as real-time PCR assays, which provide rapid, sensitive, and specific detection of microbial pathogens within a few hours [2224]. Recently, real-time PCR assays have been developed for the detection of staphylococci directly from positive blood culture bottles in clinical microbiology laboratories [25-33]. However, these assays are limited in that although they are able to rapidly identify staphylococci and determine methicillin susceptibility, they only allow the identification of staphylococci and cannot discriminate Gram-positive cocci other than staphylococci. We hypothesized that the addition of a PCR assay targeting staphylococcal $16 S$ rRNA might mitigate this limitation and target both universal $16 \mathrm{~S} r R N A$ and staphylococcal $16 S$ rRNA. In this study, thirteen isolates that were recognized as GPCC by preliminary Gram-staining were confirmed as Micrococci and Enterococci by MicroScan system; without an assay targeting the staphylococci-specific $16 \mathrm{~S}$ rRNA, they would have been interpreted as MSCoNS by real-time PCR.

\section{Conclusions}

The direct multiplex real-time PCR assay of positive blood cultures containing GPCC can provide essential information for prompt initiation of appropriate antibiotic treatment at the critical point of infection with a turnaround time of no more than $4 \mathrm{~h}$, which includes $2 \mathrm{~h}$ for DNA extraction and $1.5 \mathrm{~h}$ for PCR. Further studies should evaluate the clinical outcome and benefit of using this rapid real-time PCR assay incorporated with conventional culture methods for glycopeptide antibiotic therapy in the case of positive blood cultures growing GPCC in clinical settings.

\section{Additional Points}

(i) We developed multiplex real-time PCR assay for rapid categorization of staphylococci. (ii) The targets were mecA, femA, universal $16 S$ rRNA, and staphylococcal $16 S$ rRNA. (iii) The results directly from positive blood culture bottles were compared with MicroScan. (iv) The assay rapidly detected methicillin-resistant staphylococci with good agreement.

\section{Competing Interests}

The authors declare that they have no competing interests.

\section{Authors' Contributions}

The first two authors, Yousun Chung and Taek Soo Kim, contributed equally to this work.

\section{References}

[1] Á. Skow, K. A. Mangold, M. Tajuddin et al., "Species-level identification of staphylococcal isolates by real-time PCR and melt curve analysis," Journal of Clinical Microbiology, vol. 43, no. 6, pp. 2876-2880, 2005.

[2] E. Gradelski, L. Valera, L. Aleksunes, D. Bonner, and J. FungTomc, "Correlation between genotype and phenotypic categorization of staphylococci based on methicillin susceptibility and resistance," Journal of Clinical Microbiology, vol. 39, no. 8, pp. 2961-2963, 2001.

[3] T. P. Lodise, P. S. McKinnon, L. Swiderski, and M. J. Rybak, "Outcomes analysis of delayed antibiotic treatment for hospitalacquired Staphylococcus aureus bacteremia," Clinical Infectious Diseases, vol. 36, no. 11, pp. 1418-1423, 2003.

[4] R. B. R. Ferreira, N. L. P. Iorio, K. L. Malvar et al., "Coagulasenegative staphylococci: comparison of phenotypic and genotypic oxacillin susceptibility tests and evaluation of the agar screening test by using different concentrations of oxacillin," Journal of Clinical Microbiology, vol. 41, no. 8, pp. 3609-3614, 2003.

[5] T. G. Krediet, E. M. Mascini, E. Van Rooij et al., "Molecular epidemiology of coagulase-negative staphylococci causing sepsis in a neonatal intensive care unit over an 11-year period," Journal of Clinical Microbiology, vol. 42, no. 3, pp. 992-995, 2004.

[6] B. Favre, S. Hugonnet, L. Correa, H. Sax, P. Rohner, and D. Pittet, "Nosocomial bacteremia: clinical significance of a single blood culture positive for coagulase-negative staphylococci," Infection Control and Hospital Epidemiology, vol. 26, no. 8, pp. 697-702, 2005.

[7] E. L. Munson, D. J. Diekema, S. E. Beekmann, K. C. Chapin, and G. V. Doern, "Detection and treatment of bloodstream infection: laboratory reporting and antimicrobial management," Journal of Clinical Microbiology, vol. 41, no. 1, pp. 495-497, 2003.

[8] M. J. Espy, J. R. Uhl, L. M. Sloan et al., "Real-time PCR in clinical microbiology: applications for routine laboratory testing," Clinical Microbiology Reviews, vol. 19, no. 1, pp. 165256, 2006.

[9] P. Francois, D. Pittet, M. Bento et al., "Rapid detection of methicillin-resistant Staphylococcus aureus directly from sterile or nonsterile clinical samples by a new molecular assay," Journal of Clinical Microbiology, vol. 41, no. 1, pp. 254-260, 2003.

[10] M. A. Nadkarni, F. E. Martin, N. A. Jacques, and N. Hunter, "Determination of bacterial load by real-time PCR using a broad-range (universal) probe and primers set," Microbiology, vol. 148, no. 1, pp. 257-266, 2002.

[11] H. Al-Talib, C. Y. Yean, A. Al-Khateeb et al., "A pentaplex PCR assay for the rapid detection of methicillin-resistant Staphylococcus aureus and Panton-Valentine Leucocidin," BMC Microbiology, vol. 9, article 113, 2009.

[12] M. Kim, S. R. Heo, S. H. Choi et al., "Comparison of the MicroScan, VITEK 2, and Crystal GP with 16S rRNA sequencing and MicroSeq 500 v2.0 analysis for coagulase-negative staphylococci," BMC Microbiology, vol. 8, article 233, 2008.

[13] A. N. Olendzki, E. M. Barros, M. S. Laport, K. R. N. Dos Santos, and M. Giambiagi-Demarval, "Reliability of the MicroScan 
WalkAway PC21 panel in identifying and detecting oxacillin resistance in clinical coagulase-negative staphylococci strains," European Journal of Clinical Microbiology \& Infectious Diseases, vol. 33, no. 1, pp. 29-33, 2014.

[14] G. L. Archer, D. M. Niemeyer, J. A. Thanassi, and M. J. Pucci, "Dissemination among staphylococci of DNA sequences associated with methicillin resistance," Antimicrobial Agents and Chemotherapy, vol. 38, no. 3, pp. 447-454, 1994.

[15] F. Martineau, F. J. Picard, N. Lansac et al., "Correlation between the resistance genotype determined by multiplex PCR assays and the antibiotic susceptibility patterns of Staphylococcus aureus and Staphylococcus epidermidis," Antimicrobial Agents and Chemotherapy, vol. 44, no. 2, pp. 231-238, 2000.

[16] E. Galdiero, G. Liguori, M. D’Isanto, N. Damiano, and L. Sommese, "Distribution of mecA among methicillin-resistant clinical staphylococcal strains isolated at hospitals in Naples, Italy," European Journal of Epidemiology, vol. 18, no. 2, pp. 139145, 2003.

[17] J. L. Gerberding, C. Miick, H. H. Liu, and H. F. Chambers, "Comparison of conventional susceptibility tests with direct detection of penicillin-binding protein $2 \mathrm{a}$ in borderline oxacillin-resistant strains of Staphylococcus aureus," Antimicrobial Agents and Chemotherapy, vol. 35, no. 12, pp. 2574-2579, 1991.

[18] A. Jain, A. Agarwal, and R. K. Verma, "Cefoxitin disc diffusion test for detection of meticillin-resistant staphylococci," Journal of Medical Microbiology, vol. 57, no. 8, pp. 957-961, 2008.

[19] L. Jukes, J. Mikhail, N. Bome-Mannathoko et al., "Rapid differentiation of Staphylococcus aureus, Staphylococcus epidermidis and other coagulase-negative staphylococci and meticillin susceptibility testing directly from growth-positive blood cultures by multiplex real-time PCR," Journal of Medical Microbiology, vol. 59, no. 12, pp. 1456-1461, 2010.

[20] A. Kilic, K. L. Muldrew, Y.-W. Tang, and A. C. Basustaoglu, "Triplex real-time polymerase chain reaction assay for simultaneous detection of Staphylococcus aureus and coagulasenegative staphylococci and determination of methicillin resistance directly from positive blood culture bottles," Diagnostic Microbiology and Infectious Disease, vol. 66, no. 4, pp. 349-355, 2010.

[21] Y.-W. Tang, A. Kilic, Q. Yang et al., "StaphPlex system for rapid and simultaneous identification of antibiotic resistance determinants and Panton-Valentine leukocidin detection of staphylococci from positive blood cultures," Journal of Clinical Microbiology, vol. 45, no. 6, pp. 1867-1873, 2007.

[22] S. Klaschik, L. E. Lehmann, A. Raadts et al., "Detection and differentiation of in vitro-spiked bacteria by real-time PCR and melting-curve analysis," Journal of Clinical Microbiology, vol. 42, no. 2, pp. 512-517, 2004.

[23] T. Mohammadi, H. W. Reesink, C. M. J. E. VandenbrouckeGrauls, and P. H. M. Savelkoul, "Optimization of real-time PCR assay for rapid and sensitive detection of eubacterial 16S ribosomal DNA in platelet concentrates," Journal of Clinical Microbiology, vol. 41, no. 10, pp. 4796-4798, 2003.

[24] H. Sakai, G. W. Procop, N. Kobayashi et al., "Simultaneous detection of Staphylococcus aureus and coagulase-negative staphylococci in positive blood cultures by real-time PCR with two fluorescence resonance energy transfer probe sets," Journal of Clinical Microbiology, vol. 42, no. 12, pp. 5739-5744, 2004.

[25] A. Huletsky, P. Lebel, F. J. Picard et al., "Identification of methicillin-resistant Staphylococcus aureus carriage in less than
1 hour during a hospital surveillance program," Clinical Infectious Diseases, vol. 40, no. 7, pp. 976-981, 2005.

[26] W. C. Lindsey, E. S. Woodruff, D. Weed, D. C. Ward, and R. D. Jenison, "Development of a rapid diagnostic assay for methicillin-resistant Staphylococcus aureus and methicillinresistant coagulase-negative Staphylococcus," Diagnostic Microbiology and Infectious Disease, vol. 61, no. 3, pp. 273-279, 2008.

[27] N. K. Shrestha, M. J. Tuohy, G. S. Hall, C. M. Isada, and G. W. Procop, "Rapid identification of Staphylococcus aureus and the mecA gene from BacT/ALERT blood culture bottles by using the LightCycler system," Journal of Clinical Microbiology, vol. 40, no. 7, pp. 2659-2661, 2002.

[28] T. Y. Tan, S. Corden, R. Barnes, and B. Cookson, "Rapid identification of methicillin-resistant Staphylococcus aureus from positive blood cultures by real-time fluorescence PCR," Journal of Clinical Microbiology, vol. 39, no. 12, pp. 4529-4531, 2001.

[29] C. Palomares, M. J. Torres, A. Torres, J. Aznar, and J. C. Palomares, "Rapid detection and identification of Staphylococcus aureus from blood culture specimens using real-time fluorescence PCR," Diagnostic Microbiology and Infectious Disease, vol. 45, no. 3, pp. 183-189, 2003.

[30] S. M. Paule, A. C. Pasquariello, R. B. Thomson Jr., K. L. Kaul, and L. R. Peterson, "Real-time PCR can rapidly detect methicillin-susceptible and methicillin-resistant Staphylococcus aureus directly from positive blood culture bottles," American Journal of Clinical Pathology, vol. 124, no. 3, pp. 404-407, 2005.

[31] S. Gröbner and V. A. J. Kempf, "Rapid detection of methicillinresistant staphylococci by real-time PCR directly from positive blood culture bottles," European Journal of Clinical Microbiology \& Infectious Diseases, vol. 26, no. 10, pp. 751-754, 2007.

[32] L. C. Thomas, H. F. Gidding, A. N. Ginn, T. Olma, and J. Iredell, "Development of a real-time Staphylococcus aureus and MRSA (SAM-) PCR for routine blood culture," Journal of Microbiological Methods, vol. 68, no. 2, pp. 296-302, 2007.

[33] J. Stratidis, F. J. Bia, and S. C. Edberg, "Use of real-time polymerase chain reaction for identification of methicillinresistant Staphylococcus aureus directly from positive blood culture bottles," Diagnostic Microbiology and Infectious Disease, vol. 58, no. 2, pp. 199-202, 2007. 

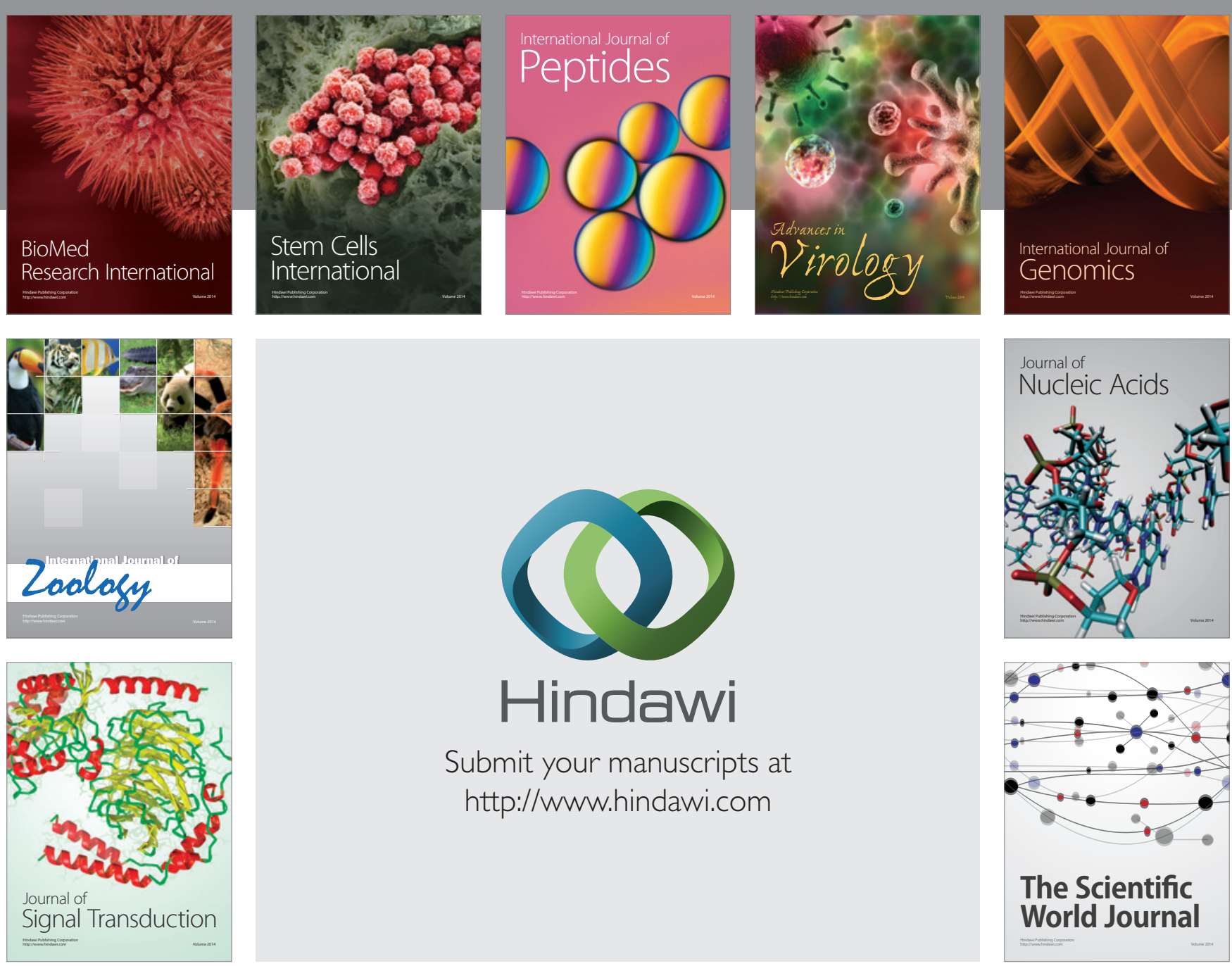

Submit your manuscripts at

http://www.hindawi.com
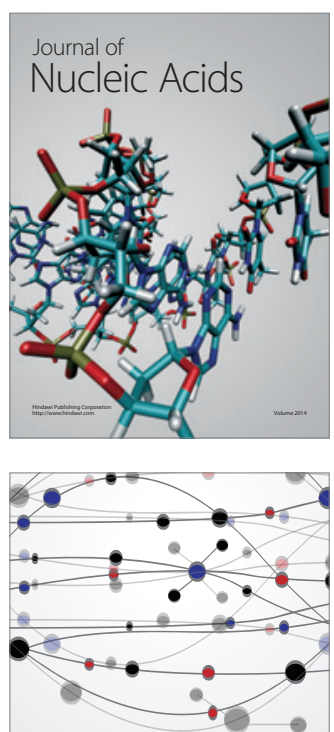

The Scientific World Journal
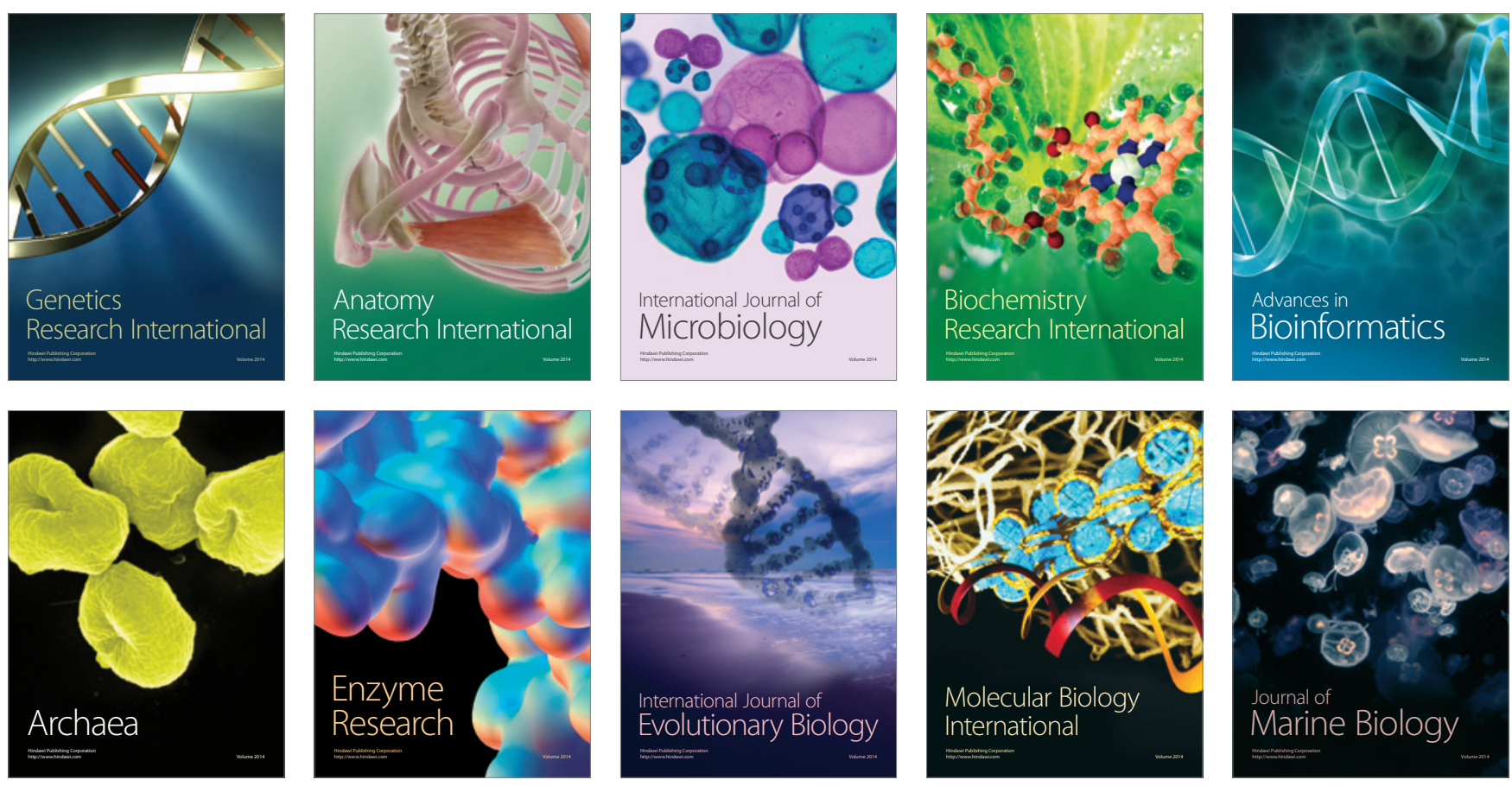